流れの可視化 Vol.2 Suppl.(1982年11月)

コンピュータを㐫用した流れの可視化

千菜大・工中博

\title{
A Brief Review of Applications of Computer to flow Visualization
}

Hirosh 1 Nakaguchi**

\begin{abstract}
A brief review of the Computer-Aided Flow Visualization (CAFV) is presented. CAFV is a powerful new technique in view of the recent requirements placed on flow visualization. Some unique capabilities of CAFV are described, those are enhencement of pictures, transformation of observer's coordinate, image processIng of measured data, disclosure of hidden phenomena from chaotic observation by means of ingenious mathematical treatments, etc. Illustrative examples are shown, and some problems of CAFV to be solved are presented as well.
\end{abstract}

1 まおき

2 次元定常流孔では流跡，流脤およじ流線が一致し，兰こで流れの可視化は最 主有都に使われる。.2次元流れに比心゙て3次元流飞では流れの槽造の把握が急に

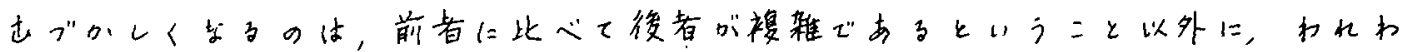
北の思考が2次元的であることによるように思われる。しのし，流体栈械設計

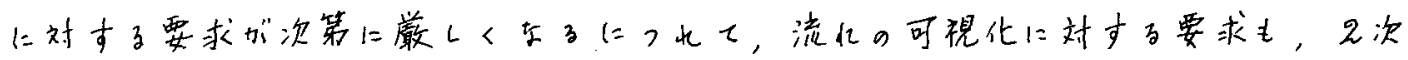

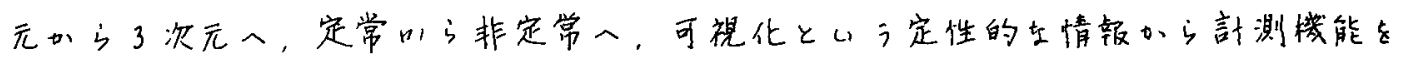

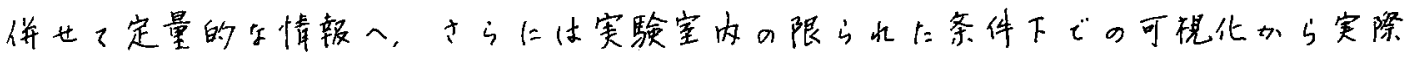
の流体栈械の作動状况下におけ子可視化へ上䓋が，て来ている。

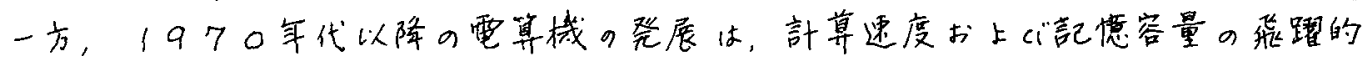
子增大七画像処理棫能の强化か门，リモ一ト七ンシブやいか中る数值流体力学の 発展を促し，流体，熟およu物筫の流水の可視化にも有力む手段文提供する小う になつた。流北の可視化国绦シンポ:゙ウムの登表論文心引是ると，1977年に

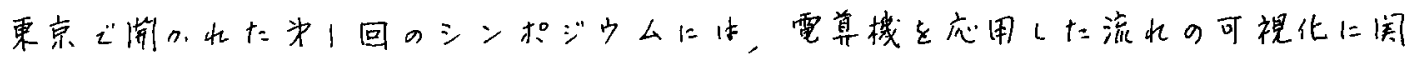

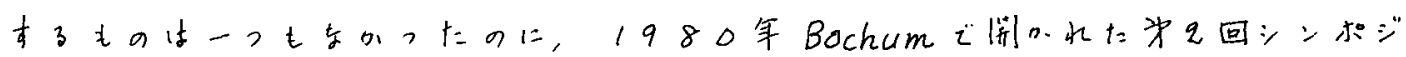

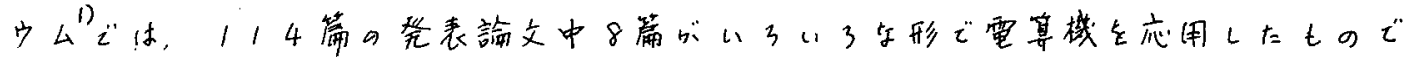

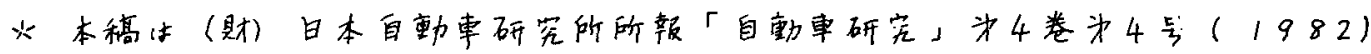
に投䅛した「流水の可視化技街の動向上課题」の一部を補足にたものでるる。

** Faculty of Engineering, Chiba University, 1-33, Yayoicho, Chiba 260, Japan 


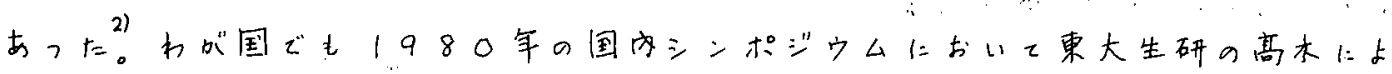

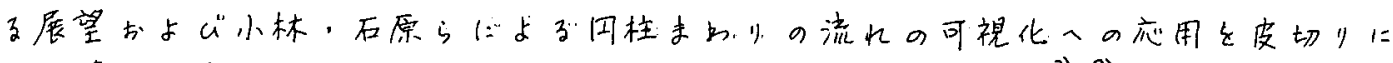

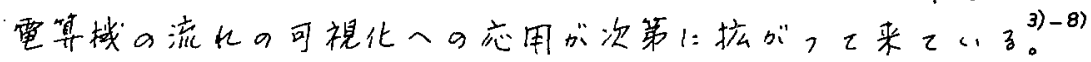

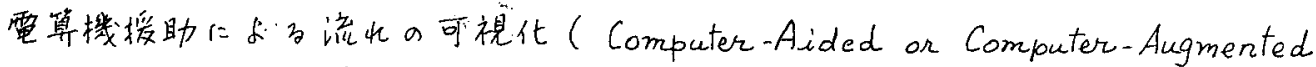
How Visualization) \&以F $i$ iCAFVr呼si $=r i \frac{t}{d}$ 。

\section{$2 C A F V$ a 特徽}

在来の方法で可視さ九子流必の像小，流脤；流跡(速度べクトルの投影)，夕 イムライン，密度偭斜古るいは自由表面の四凸むど，適用する手法によってさま ざまであるが，本来的にアナログ量でする。これに対してCAFVではすびての

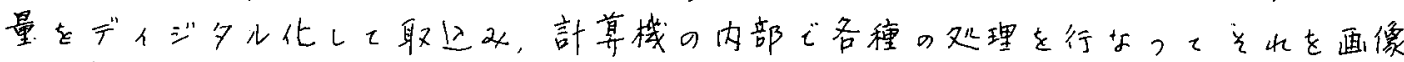

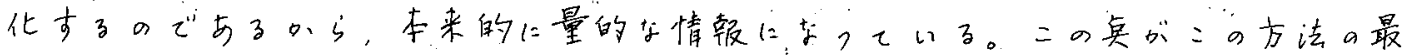

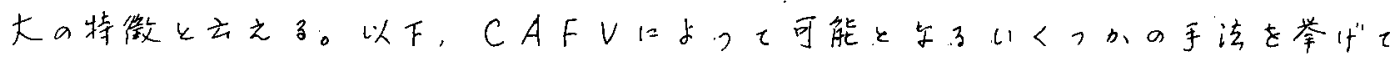
斿。

\section{3. 画質口改良}

流䟽法をとによって可視化された流れの像、りるいはシュリーレン法タとによ

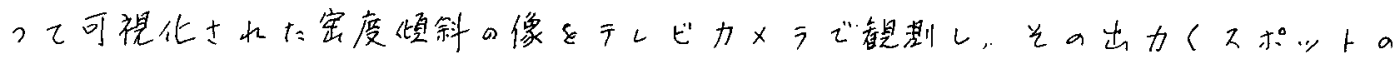

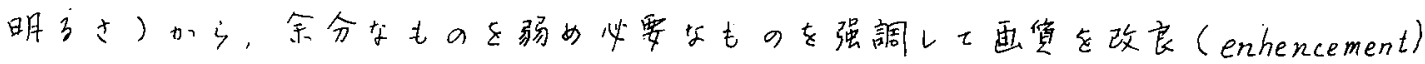

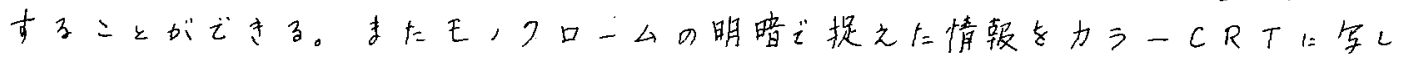
出し, 色相の变化に变之ることができる。れは人間の䄈賞茄明暗の度合い上り 毛色相の娈化に対して鋭敏で可ることによる。サーモブラフの多くの毛のは物体 表面の温度分布を温度管每心色别忙儿表示市るし，地球探查衙星(Landsat) の計湿かう地球上の植生をどを力う一表示する例をとは良く知うれている。

\section{4. 钼測者(器) の座摽变換}

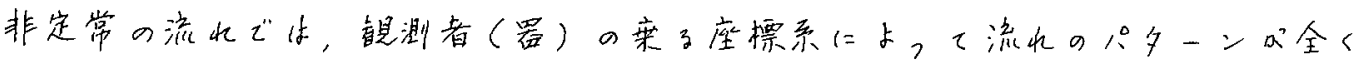

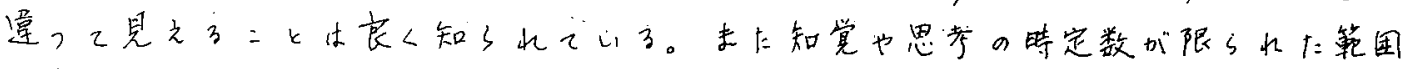
に古るわ水われの目によ,て，特性時間が巾㕕く变わる現実の流九を通常の方法 により害時间で钼祭しただけでは，流の棈造を把握しにくいことがある。CAF

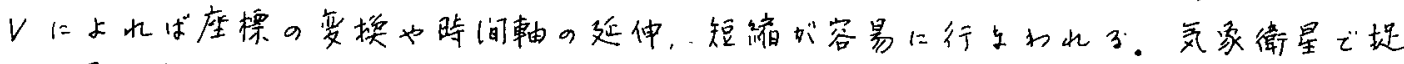

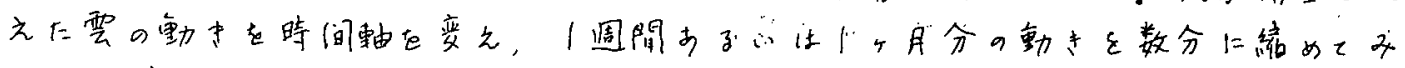

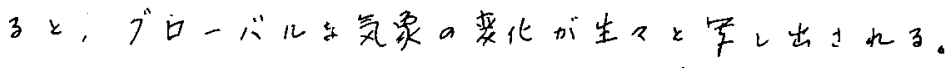

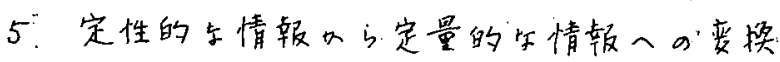

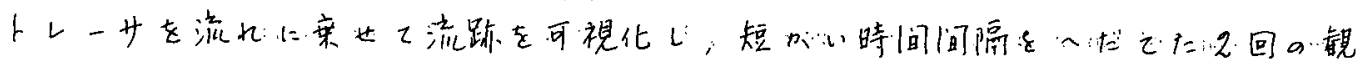




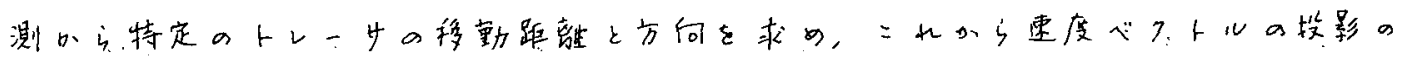
分布を求のることができる。気象衛星による钼澌では雲とトレーサとして地球上 の风向凡速分布を水めることがず゙にルーチンとして行なかれている。

\section{6. 量的計测結果の画像表示}

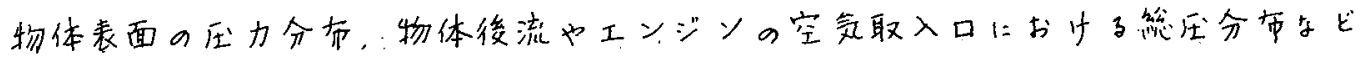
は，多数ではあるが離散的に設けられた静压管または統压管とスキャニバルブ・

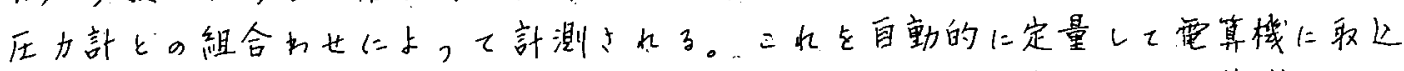

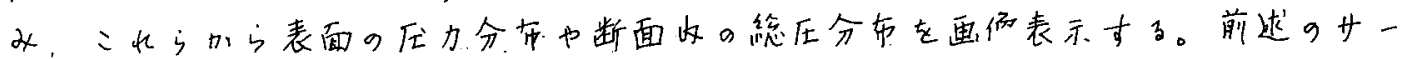
モグラン生同㴍の手法でCRT上に表示さ水にもので，二の方法は計测時间の短 縮や省力化に毛有效である。

\section{7 援された情報の抽出}

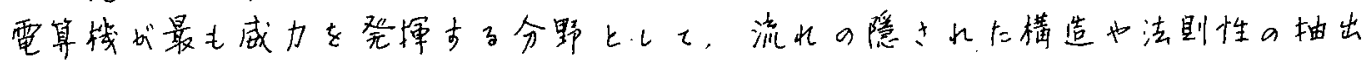
がある。非定常流儿，特に激しい速度变動を伴;乱流境界層や後流内の流九を可

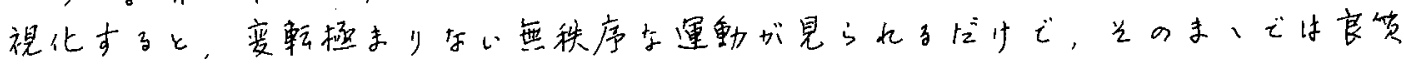

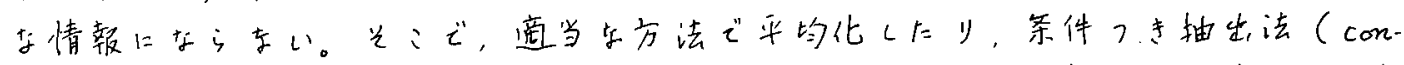

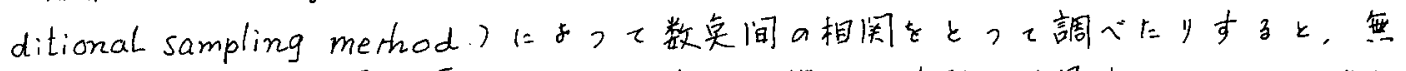

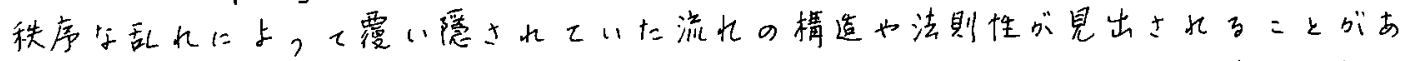

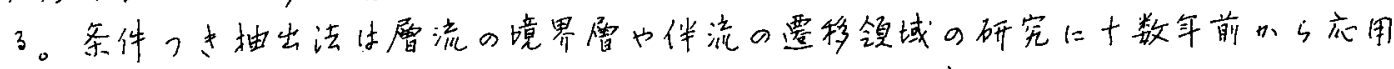

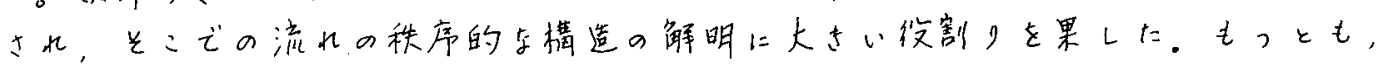

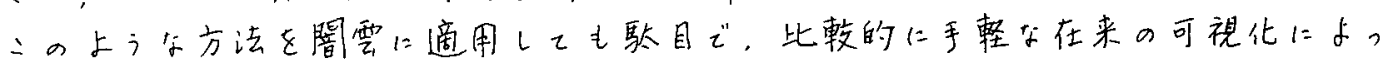

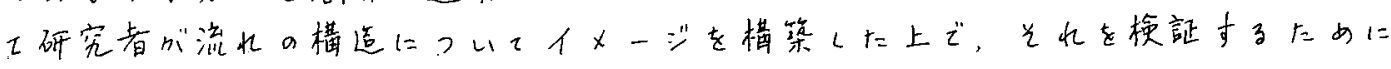
最適学缏計画を立てて適用する必要がある。

\section{CAFVa問题卓}

以上逑へた上引にＣＡＦＶは流水の可視化，特に了次元非定常流の可视化に

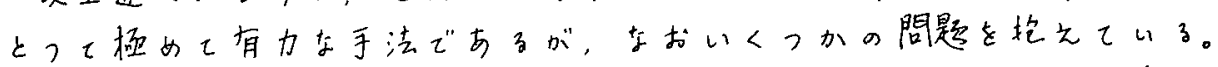

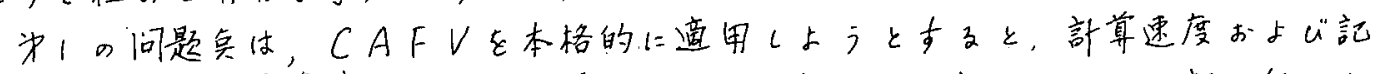
憶容量の大きい電算械が必要で，現在のと: 何处で誰でもという訳に行か子 いニとでする。当面マイクロコンピュータの活用によって部分的をC A F V を行

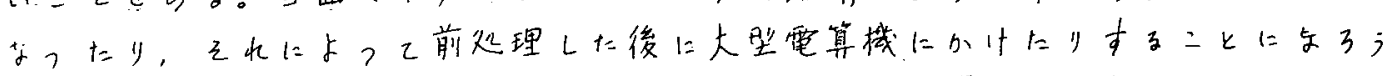

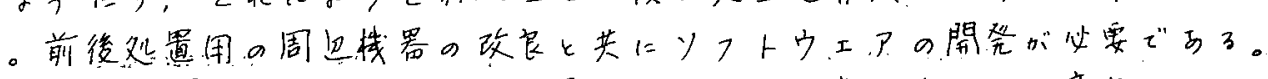

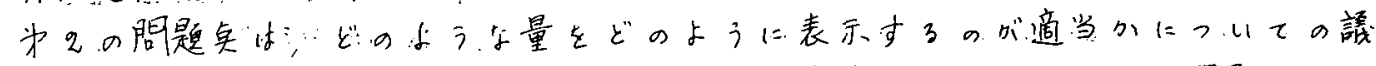

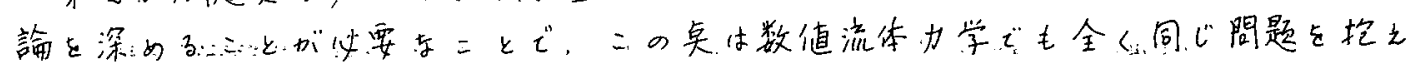

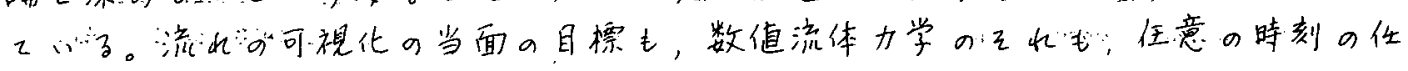




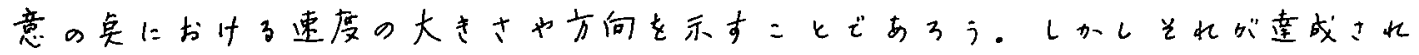

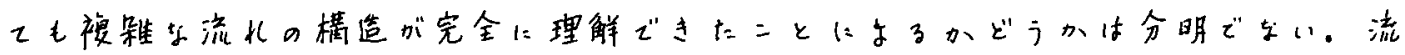

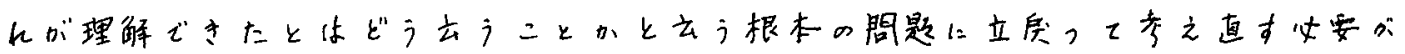

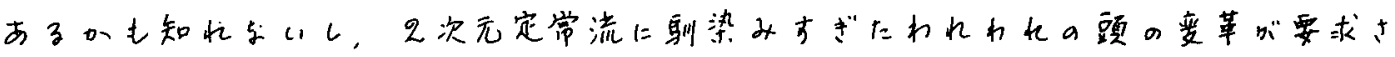
九子分毛知孔をい。

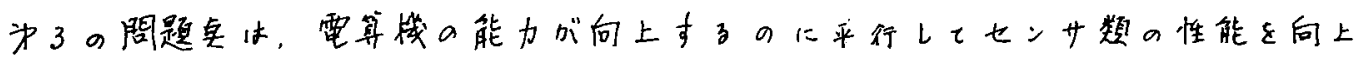
さ世子必要がある。多数实での圧力や速度べフトルの同時計测について现在かれ

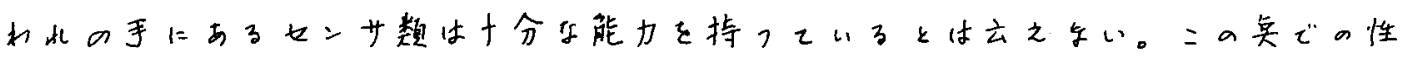
能を向上すると共に，实際の流体栈诚の稼動条件下での可視化に使之るようよ七 ンサ数の闹登が望まれ了。

\section{9.}

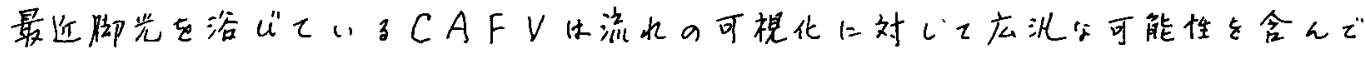
いる。多くの若い斫究者の媛れた着想を加えることによってそれらが实を結じ，

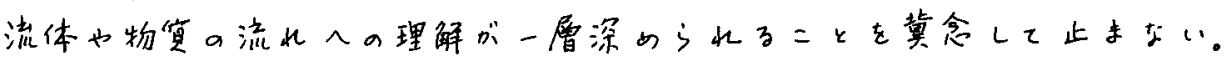

\section{文献}

1) International Symposium on Flow Visualization, Bochum, Germany, Sep. 9- 12, 1980, Preprint

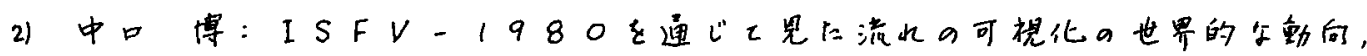
流九可可视化，Vol. 1 ，No. 1 ( (1981) pp. 18-23.

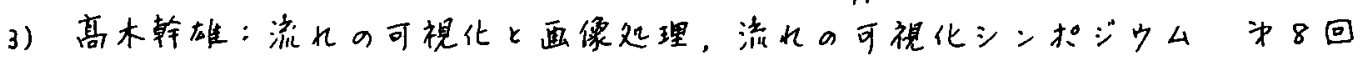
( 1980 )，更京大学宇宙航空研究所， pp V - XV.

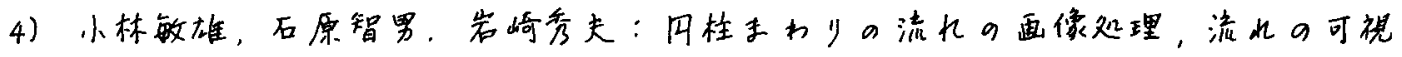

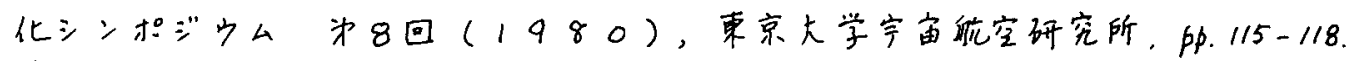

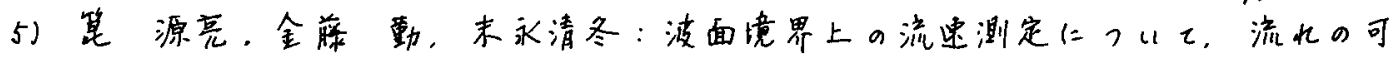

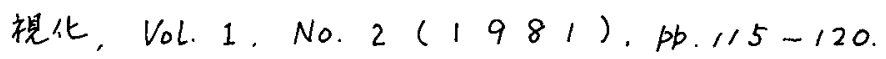

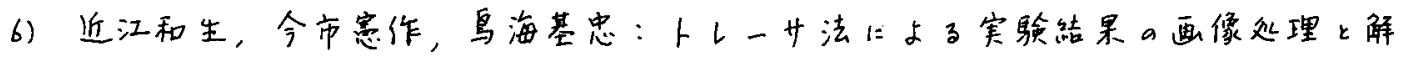

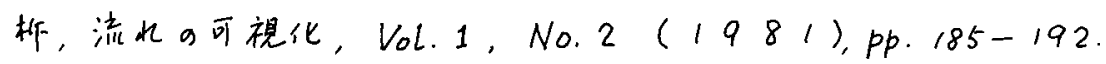

7) Wen-Jei Yong : Flow Visualization by Computer-Generated color Grafic Technique, 流凡a可视 化, Vol. 2, No.6 (1982)，Pp. 401-408.

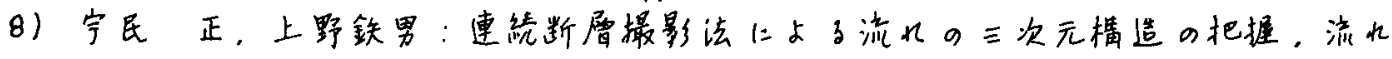
の可視化，Vol. 2, No.6 (1982), pp 415-420.

9) P. Bonmarin: Laboratory Observation of Gravity Waves Breaking on Deep Water, International Symposium on Flow Visualization, Bochum, Germany, Sep. 9-12, 1980, pp. 267-271.

10) R. Gallington and G. Sisson: Flow Visualization Using a Computerized Data Aquisition System, International Symposium on Flow V1sualization, Bochum, Germany, Sep. 9-12, 1980, pp.124-141. 
11) Yoji Ishida: A Numerical Study of Flow Past a Rotating Flat Plate by The Diacrete Vortex Method, Trans. Japan Soc. for Aeronautics \& Space Sciences, Vol. 25, No. 68 (1982), pp. $114-125$.

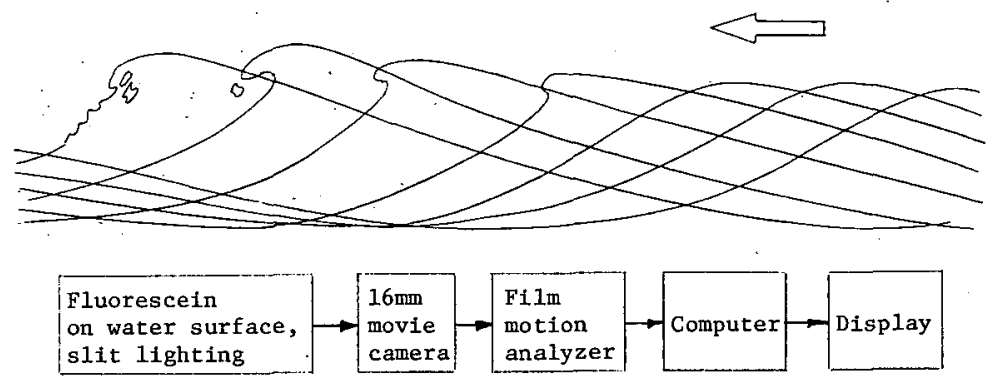

Fig. 1 Breaking phenomena of gravity waves ( P. Bonmarin, IMST, France )
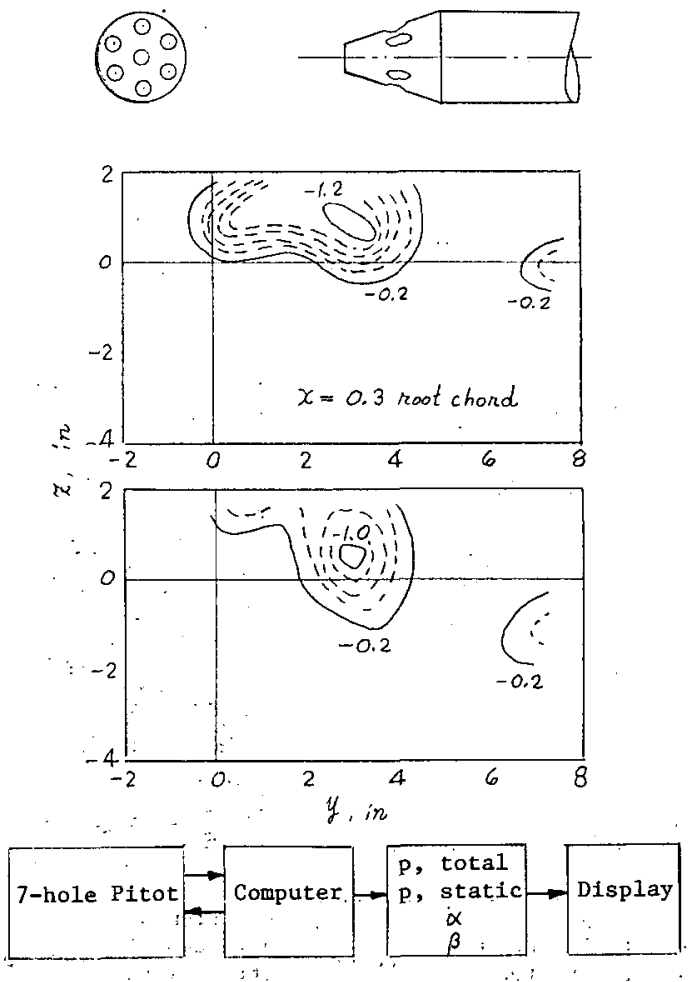

Fig. 2 Total pressure distribution behind a canard plane ( R. Gallington and G. Sisson, USAF Academy ) 


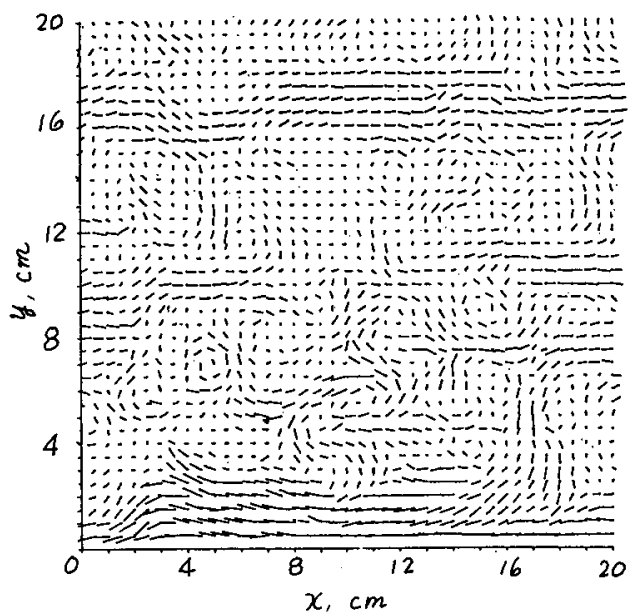

Projected velocity vector

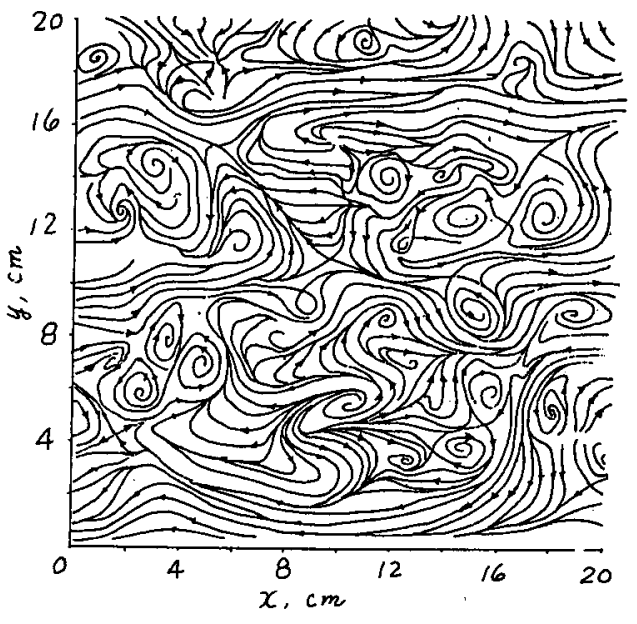

Instantaneous stream line

\begin{tabular}{|c|c|c|c|c|c|}
\hline $\begin{array}{l}\text { Solid tracer, } \\
\text { slit lighting }\end{array}$ & $\begin{array}{l}\text { Still } \\
\text { picture }\end{array}$ & $\begin{array}{l}\text { Projected } \\
\text { velocity } \\
\text { vector } \\
\text { (manual) }\end{array}$ & Computer & $\begin{array}{l}\text { Stream line, } \\
\text { vorticity } \\
\text { distribution }\end{array}$ & Display \\
\hline
\end{tabular}

Fig. 3 Three-dimensional structure of turbulent flow ( T. Utami and T. Ueno, Kyoto Untversity )

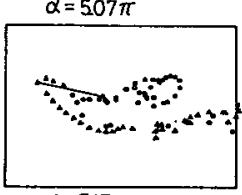

$\alpha=5.17 \pi$

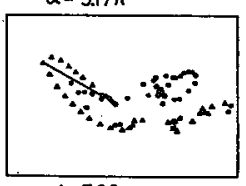

$\alpha=5.36 \pi$

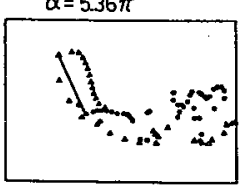

$\alpha=5,46 \pi$

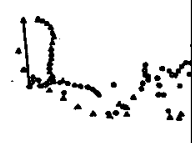

$\alpha=5.57 \pi$

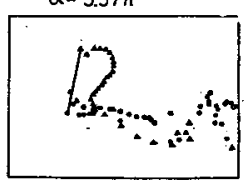

$\alpha=5.77 \pi$

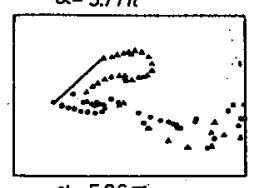

$\alpha=5.96 \pi$

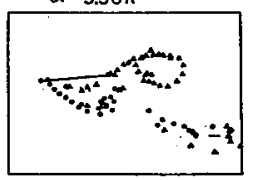

Position of vortices $\alpha=5.10 \pi$

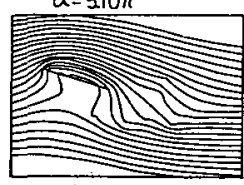

$\alpha=520 \pi$

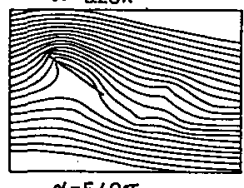

$\alpha=5.40 \pi$

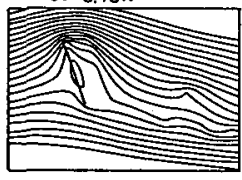

$\alpha=5.50 \pi$

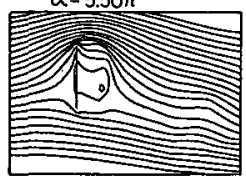

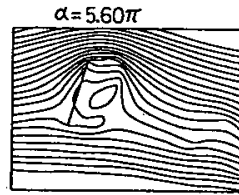

$\alpha=5.80 \pi$

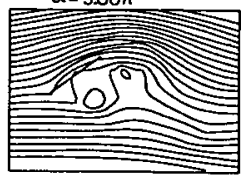

$\alpha=5.99 \pi$

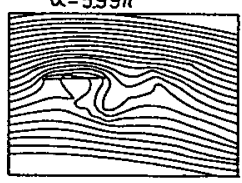

Instantaneous stream IIne

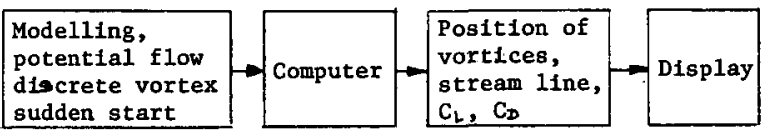

F1g. 4 Flow past a rotating flat plate (compuation) ( Y. Ishida, National Aerospace Laboratory) 